\title{
Marine Environmental Management and Development Strategy for Marine Aquaculture in Taiwan: Cobia Case Study
}

\author{
Yi Che Shih ${ }^{1,2,3 *}$ \\ ${ }^{1}$ Deputy of Director, Ocean Affairs Council, Executive Yuan, Kaohsiung City 80661, Taiwan \\ ${ }^{2}$ Assistant Professor, Department of Maritime Police, National Central Police University, Taiwan \\ ${ }^{3}$ Assistant Professor, Institute of Ocean Technology and Marine Affairs, National Cheng Kung University, Taiwan
}

*Corresponding author: Yi Che Shih, Assistant Professor, National Cheng Kung University, Taiwan.

Received Date: August 25, 2018

Published Date: Septembert 14, 2018

\begin{abstract}
Taiwan is surrounded by the sea. As regards to its lands and resources are limited. To develop the marine culture is the government's fishery policy in recent decades. However, in the process of vigorous sea culture, if there is a lack of marine environmental related policies, marine environmental monitoring systems or marine environmental monitoring indicators, it will have an impact on the ecological environment, environmental carrying capacity and environmental conditions of the aquaculture environment. Therefore, this paper reviews and focuses on the environmental conditions, management and development strategies of Taiwan's marine aquaculture. Moreover, to propose strategies to enable the future development of Taiwan marine aquaculture environment and aquaculture industry to get better development.
\end{abstract}

Keywords: Marine aquaculture; Marine environmental management; Marine environmental monitoring; Taiwan

\section{Introduction}

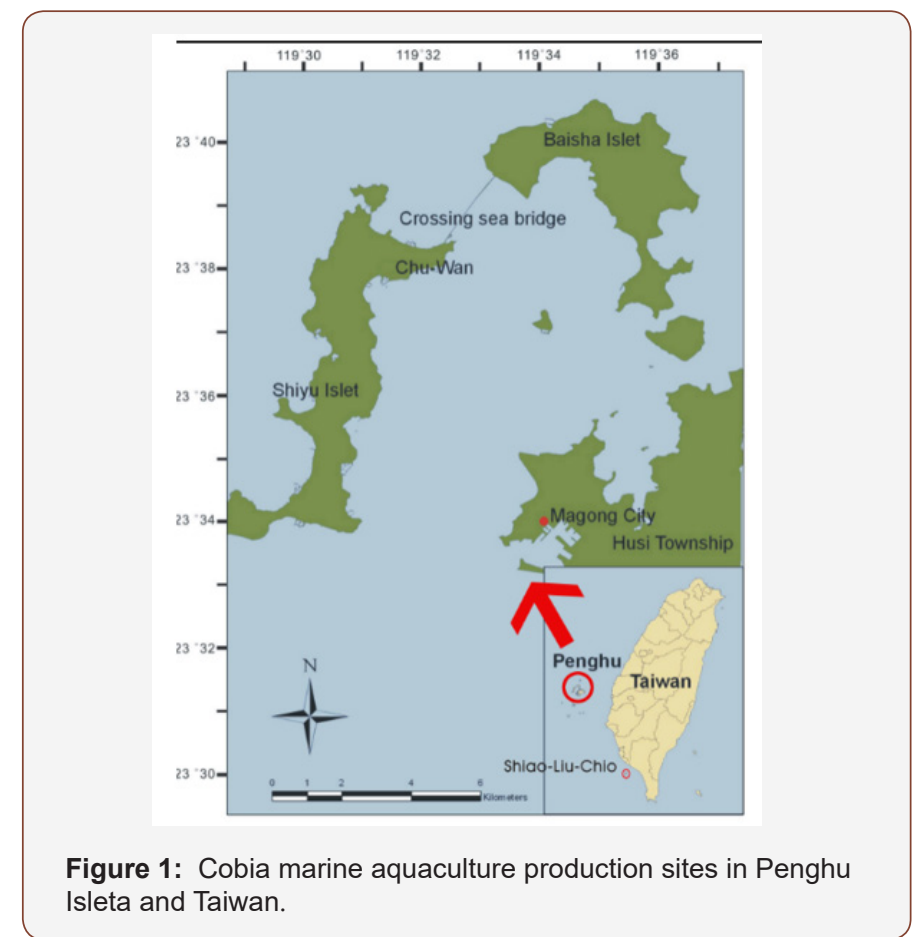

The marine aquaculture industry has been playing such an increasingly important role in food production that it has been referred to as one of the most promising industries in the world. To cite a few examples of its success, according to the United Nations Food and Agriculture Organization (FAO), total global production of cultured salmon and trout is expected to almost double from 1.77 million mt (metric tons) in 2000 to 3.50 million mt in 2010. In 2016 the production reached 937,470 $\mathrm{mt}$. As for total annual seafood production harvested from aquaculture, the U.S.A. industry, in striking contrast to its present total value of US\$900 million with some 18,000 employees [1]. is expected to have a total value of some US $\$ 50$ billion, while offering 600,000 job opportunities by 2025. In 2017, Taiwan fisheries production over 1.07 million metric tons (MT) of fish valued at $\$ 95.58$ billion New Taiwan dollars (NTD) or $\$ 3$ billion United States dollars, according to the Fisheries Year Book 2017 [2]. Because of this high demand, the Taiwanese government has supported the development of modern offshore fish farms in recent decades. Originally, marine cage aquaculture began in Taiwan in the 1970s in the Penghu Archipelago (Figure 1) to provide fish harvests from coastal fisheries. However, finite 
resources and the land-based expansion of the Taiwanese culture have caused environmental degradation. What figures such as these clearly demonstrate is that the development of aquaculture is quickly intensifying its close relationship not only to the security of food the world over but also to the benefit of local economies?

This phenomenon is no less true for Taiwan, including each region of Taiwan water, such as Penghu, Kinmen, Matzo and many other islands which, in part due to geographic considerations, is heavily dependent on the ocean and, naturally, their coastal resources. For one, Taiwan ranks top ten on the world production of far seas fisheries. Its production capacity of tuna and squid is also among the world's top providers. All the while, aquaculture in Taiwan has been being developed rapidly partially on account of the depletion of its inshore fishing resources. This may not, however, be a positive development from some points of view. To be sure, unless measures for proper management are taken, certain side effects are inevitable. Land subsidence, considered one of the most serious problems along the west coast of Taiwan Island, serves as one example here. This problem, it is believed, is attributable to an over-pumping of the groundwater that is used for coastal aquaculture. Based on an investigation by the Water Conservancy Administration, the issue of land subsidence is particularly aggravated in Pingtung County, where land has sunk about $3.5 \mathrm{~m}$ over the past several years. Almost just as bad is the subsidence rate in Changhua County which is estimated at $18.5 \mathrm{~cm}$ annually. The total area identified as being affected by land subsidence in Taiwan's southwestern coastal zone is over 1,100 km2 or more than $10 \%$ of Taiwan's flat land [3]. Obviously, this situation has increased the risk of flooding industrial and private property and poses a serious threat to human life in coastal areas. The gravity of the situation, therefore, has forced the government to adopt more aggressive measures to mitigate the negative impact from inland aquaculture. Among these measures, and important ones at that, have been to win the support of the Fishery Administration, and prioritize the issue, thereby making harmony between the coastal environment and the economy more of an important policy in Taiwan.

\section{Aquaculture Environmental Status}

The total length of coastline of the Taiwan is about 1,600 km, while the total area of shallow seas is less than $30 \mathrm{~m}$ deep and adequately suitable for marine aquaculture. According to the 2017 Fisheries Year Book that total cage culture reaches 300,000 ha. With the depletion of coastal fisheries resources and the good price of cultured fish, marine cage aquaculture is becoming popular in areas where land and freshwater resources are limited.

The marine aquaculture or cage aquaculture in Taiwan started in 1977 in Penghu archipelago in the southwestern area of Taiwan. In 1995, a large scale of marine aquaculture could be found in the seas in both Penghu County and Pingtung County. Currently, the major farms of marine aquaculture are in Western Taiwan while some of them are scattered in Eastern Taiwan. In the beginning, the most popular cages are HDPE type from Norway. Nevertheless, these types of cages are vulnerable to typhoons. Experts from fisheries research institutions and academia are conducting researches to develop a new type of cages that could be submerged during strong winds and typhoons. Major species cultured in cages are cobia, spangled emperor, mangrove red snapper and grouper. Among many species of cultured marine fish, cobia is a prominently popular species for cage aquaculture because of its fast growth rate and comparatively low production cost. Cobia, Rachycentron canadum, is widely distributed in tropical and sub-tropical waters, and has been cultured as a recreational fish species. The fish can grow up to $6 \mathrm{~kg}$ during their first year and over $15 \mathrm{~kg}$ for their second year. The largest cobia can reach $1.5 \mathrm{~m}$ in length and over $40 \mathrm{~kg}$ in weight. In recent years, its potential for aquaculture was recognized because of its quality of meat. In Taiwan, cultured cobia has become popular for domestic consumption or for export, mainly to Japan. Marine culture began in the early 1990's when the technology of mass fry production was developed. To date, several marine fish hatcheries are producing cobia fingerlings to stock in nursery tanks or inshore cages. Total cobia production increased from 1,800 mt in 1999 to 3,000 mt in 2001 but plunged to 1,000 mt in 2002 due to high incidence of disease outbreaks and losses from typhoon damage [4]. The production of cobia in 2017 is $1615 \mathrm{mt}$, and its output value is 624.6 million NTD.

Marine cage culture is popular in Taiwan but regulations for open ocean aquaculture are still lacking. As cobia cannot survive below $16^{\circ} \mathrm{C}$, most of the sea cages are located in Southern Taiwan where tropical climate prevails. These areas, however, are also utilized for fishing and other purposes, thus competition for available sea area is apparent. The government plays an important role in the overall development of the cobia culture industry. However, the current policy on aquaculture is inappropriate for cobia cage culture industry. Aside from the disease outbreaks and some environmental problems, the lack of good planning and regulatory enforcement when cobia was developed as a potential aquaculture species has led to non-sustainable production in the past few years. Some policies even hinder further development of cobia culture in offshore cages. Thus, Taiwan loses international competitive advantage for the export industry among other Asian countries, who are venturing into cobia cage culture. With the high risk associated with offshore cage aquaculture, the lack of insurance policy from the government is of serious concern for most cage farmers.

Although aqua farmers in Taiwan Area face many disease and environmental problems, cobia remains to be the most popular species for culture in offshore cages. This is because of its fast growth, high market value, good meat quality, the established technology in mass production of larvae, the current innovation in intensive and super-intensive nursery rearing in tanks, and improved formulated feeds. However, the lack of regulations in open ocean aquaculture in Taiwan has resulted in the uncontrolled proliferation of sea cage farms. Disease outbreaks still remain to be the biggest threat in marine and cobia culture in Taiwan, causing a significant decline in total production in 2002. At present, research on the development of vaccines against major bacterial pathogens (P. damsela subsp. piscicida, V. alginolyticus, and Streptococcus sp.) is ongoing. Another alternative approach to this problem is the use of immunostimulants (e.g. levamisole, etc.) to enhance the nonspecific 
immunity of fish to various diseases. Stocking of more resistant large-sized fish in offshore cages also contributed in preventing apparent loss of stocks due to diseases. Disease surveillance must also be strengthened and continuously undertaken to monitor disease outbreaks. Moreover, selective breeding must also be urgently employed for improving both growth and resistance to diseases.

With the recent developments in both nursery and grow-out culture of cobia, improvement in many aspects of production is still needed. Automation in terms of feeding, grading, thinning, harvesting and net washing are still needed to be developed as these activities are highly labor intensive especially in offshore grow-out cages. The recent innovation of the intensive and super-intensive recirculating system for nursery rearing can only be applied to rearing cobia juveniles up to $300 \mathrm{~g}$. This system allows the transfer of cobia juveniles directly into offshore nursery cages in the same area where the grow-out cages are located. This strategy prevents the occurrence of high mortality due to transportation stress of large-sized cobia. However, this system might be too expensive for many fish farmers since high investment is necessary to setup the facilities. Therefore, other strategies in mass-production of cobia juveniles during the nursery stage need to be developed. One possibility is to culture cobia in ponds under a semi-intensive or intensive system. If this is successful, however, transportation problems will still be an issue to be resolved.

\section{Carrying Capacity Assessment Mechanism of Environment}

It has been a general assumption that the marine environment has a certain assimilative or environmental capacity. This presumes that all environments have a finite ability to accommodate exploitation or contamination without unacceptable consequences. Marine aquaculture may also cause environmental degradation from feces, uneaten feed and use of chemicals if the local carrying capacity is exceeded $[5,6]$. Marine aquaculture of finfish has become increasingly intensive in recent decades, primarily due to the introductions of new technologies, the expansion of suitable sites, improvements in feed technology, an improved understanding of the biology of the farmed species, improved water quality within farming systems, and an increased demand for fish products [79]. Such intensive development of the industry is now widely understood to have had a severe impact on the environment [10].

Thus, it is necessary to regulate such consent to discharge by giving a condition upon careful monitoring to ensure that the assimilative capacity is not exceeded. However, studies on or attempts to model the impact of aquaculture or some other industrial development are often undertaken well after the development activity is established. By that time, the economic commitment by the private and public sectors is too great to substantially change the path of development if monitoring results demonstrate adverse environmental effects. If the tools of scientific modeling are to be used meaningfully, they must be used prior to development. Therefore, the project is design to resolve all these concerns. It is imperative to develop an appropriate methodology to assess the environmental risk related to the net-pen aquaculture activities in the marine environment. The Carrying Capacity assessment mechanism are to investigate: [1] the environmental capacity for understanding the cumulative effects of aquaculture wastes; [2] the method for detecting the eco-response and the changes of the marine environment from the aquaculture operation; [3] the use of indigenous species and sediments from the cage to quantify the distance of impact; [4] the guidelines or environmental quality standards for the marine farming industry to assure the sustainable use of marine environment.

\section{Institutions on Aquaculture Development and Management}

\section{Policy, law and regulations}

The fundamental policy of aquaculture in Taiwan is to limit inland aquaculture to mitigate the problem of land subsidence and to encourage the development of marine aquaculture. The Fisheries Act and its enforcement regulations serve as the basic provisions in dealing with the issues of fisheries management and fishing rights on the seas. The policy on the development and management of aquaculture related to the sustainable marine environment is undergoing.

\section{Financial support}

In addition to diseases, weather conditions and typhoons represent the major threat to marine aquaculture in the Taiwan Area. The Fisheries Administration provides, if necessary, financial support measures (e.g., loans for typhoon loss) for fishermen. With very low interest, fishermen use loans to buy new facilities for marine aquaculture.

\section{Promotion of seafood}

To increase consumption of local seafood, many promotional activities for maricultural products have been created, such as the annual Penghu Sailboard and Cobia Tourism Festival. Participants are offered a chance to get away from the cares of everyday life to relax in the slow-paced atmosphere of these fascinating islands. Numerous activities are planned by organizers, which include a sailboard competition, a cobia feeding show, cobia banquet, nighttime entertainment and a special sale of Penghu local products. This activity is not only successful to attract tourists to Penghu but beneficial to the local economy.

In addition to the above institutions and measures, the achievement of aquaculture development in Taiwan includes [11]:

1. To replace the in-land fishponds, marine cage culture has been developed along with on-shore infrastructures. Assistance is also provided to fishermen in the development of maricultural of high-valued marine fish species.

2. Artificial propagation of fish seeds and the technology of mass production of fish feeds are encouraged to meet the demand of marine aquaculture operation. Research and development of seeds of high-valued and ornamental fish species are carried out to achieve requirements. Services detecting fish disease will be established to prevent epidemics and to upgrade the quality of fish seeds. 
3. The farming technique of marine fish species with potential competition in the domestic and foreign markets has been developed within the market requirement.

4. Specific aquaculture areas are planned. Farmers have been provided with knowledge of business diversity, such as the development of recreational fisheries, and the experience of fishing between parents and children to improve their income.

5. Seawater supply system in the specific aquaculture areas has been constructed and the concept of joint procurement and cooperative business operation has been promoted.

6. The flow of sea-products distribution will be shortened to improve the efficiency of marketing and to lower middlemen's cost, to ensure the interests of both producers and consumers. More efforts will be placed on exploration of new consumer groups, to create a business niche.

\section{Problems and Challenges Ahead}

The success of marine aquaculture and its intense development have inevitably caused problems in the environment that is as follows [4].

\section{Diseases}

The initial success of cobia production in the late 1990s has resulted in an increase in the number of cage farmers and an over capacity of cage operation at site to increase production. As such, several disease incidents occurred in recent years causing dramatic reduction in production during 2002. Diseases caused by bacteria, viruses and parasites occur in all stages of culture of cobia. During the larval stage, problems encountered include Epistylis and Nitzchia infestations. During the nursery stage, a viral disease (lymphocystis) is common but not fatal, as long as good water and feeding management are employed. The parasite Amyloodinium ocellatum also causes problems, which can result in high mortality. Trichodina infestation is also common during the nursery stage. Myoprotein infestation was also reported among cobia juveniles (45-80 g) reared in nursery cages causing mass mortality (about $90 \%$ within 1 month). In the grow-out stage, the ectoparasite Neobenedenia sp. is common and, together with secondary bacterial infection (by Streptococcus sp.), can cause blindness of cobia juveniles. The feeding activity of blind cobia is highly affected resulting to slower growth, dark body coloration and lower market value.

Pasteurella's, caused by the bacterium Photobacterium damsela subsp. piscicida, is one of the major problems among cagecultured cobia juveniles, especially during the onset of the winter season. Mass mortality is usually experienced when outbreaks of Pasteurella's occur. Another bacterial disease problem in grow-out sea cage culture is fibrosis. The first fibrosis outbreak was recorded in 2000, which caused $45 \%$ loss in stocks. The disease caused by Vibrio alginolytic us has characteristics of hemorrhagic lesions on skin and skeletal muscles. Other secondary invaders include V. vulnificus and V. parahaemolyticus.

\section{Environmental condition}

Taiwan Island is situated in the western Pacific Rim where strong typhoons occur annually during summer and autumn seasons. Low water temperature is encountered during the winter season in the central and northern parts of the island. Since one culture production, run of cobia for example, requires at least one year, the risk of losing stocks in offshore cages during typhoon season is high. As such, some cage farmers, especially family-owned farms, install culture cages in protected bays and coves, where water current is weak. Most of these areas, however, also harbor fishing boats, in which oil spills are common. Fish cultured in these protected areas have lower meat quality and meat often tastes oily. Over-wintering is another problem for grow-out cages in central Taiwan, especially in Penghu islands, where water temperature may drop to a low of $16{ }^{\circ} \mathrm{C}$ during the winter season. Growth of cobia is usually retarded at low temperature and sometimes, high mortality occurs when temperatures decrease to below $16^{\circ} \mathrm{C}$. As a result, culture periods in these sea-cage areas are longer (up to 17 months) compared to sea-cage areas in southern Taiwan (11-14 months) where the water temperature is between $23.5-28^{\circ} \mathrm{C}$ yearround.

\section{Others}

Cobia is not very resistant to stressors and requires high level of dissolved oxygen because of their high metabolic rates due to their active behavior. As such, mortality during transport is considered one of the most serious problems in cobia culture. Improvement in the transportation of cobia, especially juveniles, was recommended since the development of cobia culture in Taiwan, but no such improvement has yet been devised.

\section{Management Mechanism of Marine Aquaculture}

It is important to maintain the health of marine environment and the competitiveness of the aquaculture industry in Taiwan. Recommendations are provided as follows:

1. It is necessary to develop a fundamental policy of marine aquaculture in Taiwan that will fit its characteristics and the carry capacity of the marine environment to provide a direction for future development on the basis of sustainability.

2. It is important to revise the Fisheries Act so that it can provide enough marine areas for aquaculture development and a sound operation environment for the aquaculture industry. The site selection, location, scale and future development of marine aquaculture should be included in the integrated coastal management plan.

3. The scale of marine aquaculture must take the environmental carrying capacity into account. Due to the limitation of available marine areas for aquaculture, its major production should meet the demand of the domestic market instead of pursuing the economic benefits of export. Without careful consideration of the marine environment, the unlimited export of seafood production will rapidly deplete the natural resources and result in the deterioration of the marine environment.

4. It is essential to conduct studies on the methodologies of carrying capacity and risk assessment on the aquaculture seas. The related international organizations are recommended to encourage and support those countries that are interested in conducting joint projects on aquaculture research. 
5. The information exchange and multilateral cooperation and collaboration on marine aquaculture are essential and will be beneficial to the worldwide countries.

\section{Concluding Remarks}

Marine aquaculture has its potential to be one of the most costeffective industries in the world. It is believed that the promising industry will also play a crucial role to seafood production in the future. However, the environmental management aspects of marine aquaculture must be taken seriously. In this regard, countries concerned shall develop sound policies, laws and principles for the future development of the industry. More research on marine aquaculture and the international cooperation and information change on the issues are necessary to achieve the sustainable marine environment.

\section{References}

1. Liu, Chi-Yuan (2002) The status of world cage aquaculture in 20002001. Seafood and Fingerling 49.

2. Year Book of Fisheries Agency (2016), Council of Agriculture, Executive Yuan.

3. Chiau WY (1998) Coastal zone management in Taiwan: a review. Ocean and Coastal Management 38(1): 119-132.
4. Liao IC, Huang ST, Tsai WS, Hsueh MC, Chang LC, et al. (2004) Cobia culture in Taiwan: current status and problems. Aquaculture 237 (1-4): 155-165.

5. Yang CK, Chiau WY, Shih YC (2016) Sediment characteristics under and around cobia cage farms at Penghu, Taiwan, as visualized by Redox potential and sulfide content profiles using GIS as documentation tool. Journal of Aquaculture \& Marine Biology, 4(6): 1-6.

6. Wildish DJ, Keizer PD, Wilson AJ, Martin JL (2011) Seasonal changes of dissolved oxygen and plant nutrients in seawater near net pens in the macrotidal Bay of Fundy. Can j fish aquat. Sci 50(2): 303-311.

7. Shih YC, Chiu LC, Chiau WY (2009) geographic information system applied to measuring benthic environmental impact with chemical measures on mariculture at Penghu Islet in Taiwan. Science of the Total Environment. 407(6): 1824-1833.

8. De Voe MR (1994) Aquaculture and the marine environment: policy and management issues and opportunities in the United States. Bulletin of the National Research Institute of Aquaculture 1: 111-123.

9. Ross A (1997) A Review of the Environmental Impacts of Marine Salmon Farming in Scotland and Proposals for Change. Scottish Environment Link, Perth, Scotland, 92.

10. Hansena PK, Ervika A, Schaanning M, Johannessen P, Aure J, et al. (2001) Regulating the local environmental impact of intensive marine fish farming. The concept of the MOM system (Modelling_On growing fish farm_Monitoring). Aquaculture 158: 85-94.

11. Fisheries Administration (2004) Fisheries information. 